\title{
Assistência Técnica e Extensão Rural (ATER): formação e conhecimentos para a agricultura familiar do Rio Grande do Norte
}

\author{
Emanoel Márcio Nunes \\ Universidade do Estado do Rio Grande do Norte - Rio Grande do \\ Norte - RN - Brasil \\ ORCID: https://orcid.org/0000-0002-9045-887X \\ Vivian Menezes da Silva \\ Universidade do Estado do Rio Grande do Norte - Rio Grande do \\ Norte - RN - Brasil \\ Vinicius Claudino de Sá \\ Universidade do Estado do Rio Grande do Norte - Rio Grande do \\ Norte - RN - Brasil
}

\begin{abstract}
Resumo
O objetivo é analisar a formação do quadro de técnicos de Assistência Técnica e Extensão Rural e os conhecimentos necessários para engendrar processos de desenvolvimento rural, considerando que a ATER é uma política que promove a inovação na agricultura familiar através de ações específicas que modificam a realidade dos atores envolvidos. A metodologia consistiu da utilização de dados primários e secundários, sendo os primeiros da aplicação de um questionário estruturado a 135 extensionistas do Instituto de Assistência Técnica e Extensão Rural (EMATER), do Rio Grande do Norte, entre os meses de março a junho de 2018; e os segundos por meio da análise de informações, especialmente as obtidas das regionais da EMATER/RN e da Secretaria Especial de Agricultura Familiar e do Desenvolvimento Agrário (SEAD), através da Coordenação-Geral de Gestão Estratégica, Monitoramento e Avaliação (CGMA/NEAD). Como resultados, verificou-se a necessidade de um caráter menos difusionista e mais extensionista para a formação em nível técnico, tecnólogo e nível superior. E quanto aos conhecimentos prevaleceram temas relacionados com a diversificação e inovação da agricultura familiar, com vistas a inclusão e a construção de mercados.
\end{abstract}

Palavras-Chave: Agricultura familiar. Política pública. Desenvolvimento rural. Extensionista.

Technical Assistance and Rural Extension (ATER): training and knowledge for family farming in Rio Grande do Norte, Brazil

\section{Abstract}

\footnotetext{
${ }^{1}$ Este trabalho faz parte de um conjunto de pesquisas desenvolvidas no âmbito da agricultura familiar e teve financiamento do CNPq, através da Chamada Encomendas COSAE MDA 2013 (APQ).
} 
The objective is to analyze the training of Technical Assistance and Rural Extension technicians and the necessary knowledge to engender rural development processes, considering that ATER is a policy that promotes innovation in family farming through specific actions that modify the reality of rural areas and actors involved. The methodology consisted of the use of primary and secondary data. The first being the application of a structured questionnaire to 135 extensionists from the Institute of Technical Assistance and Rural Extension (EMATER), from Rio Grande do Norte, Brazil, from March to June 2018. The latter through analysis of information, especially from the regional EMATER and the Special Secretariat of Family Farming and Agrarian Development (SEAD), through the General Coordination of Strategic Management, Monitoring and Evaluation. As a result, there was a need for a less diffusionist and more extensionist character for training at the technical, technologist and higher level. As for knowledge, themes related to the diversification and innovation of family farming prevailed, considering including and building markets.

Keywords: Family Farming. Public policy. Rural development. Extensionist.

\section{Asistencia Técnica y Extensión Rural (ATER): capacitación y conocimiento para la agricultura familiar en Rio Grande do Norte, Brazil}

\section{Resumen}

El objetivo es analizar la capacitación de técnicos de Asistencia Técnica y Extensión Rural y el conocimiento necesario para generar procesos de desarrollo rural, considerando que ATER es una política que promueve la innovación en la agricultura familiar a través de acciones específicas que modifican la realidad de las áreas rurales. actores involucrados La metodología consistió en el uso de datos primarios y secundarios, el primero fue la aplicación de un cuestionario estructurado a 135 extensionistas del Instituto de Asistencia Técnica y Extensión Rural (EMATER), de Rio Grande do Norte, de marzo a junio de 2018. ; y este último a través del análisis de información, especialmente de la EMATER regional y la Secretaría Especial de Agricultura Familiar y Desarrollo Agrario (SEAD), a través de la Coordinación General de Gestión Estratégica, Monitoreo y Evaluación. Como resultado, era necesario un carácter menos difusionista y más extensionista para la formación a nivel técnico, tecnológico y superior. En cuanto al conocimiento, temas relacionados con la diversificación e innovación de la agricultura familiar, con miras a incluir y construir mercados.

Palabras clave: Agricultura familiar. Política pública. Desarrollo rural. Extensionista.

\section{INTRODUÇÃO}

A Extensão Rural no Brasil vem de meados dos anos 1940, por influência das universidades norte-americanas e por intermédio do empresário Nelson Rockfeller, no estado de Minas Gerais, sendo institucionalizada com a criação das Associação de Crédito e Assistência Rural (ACAR). A concepção da Extensão Rural, firmada progressivamente, buscava um padrão técnico capaz de melhorar as condições de vida no meio rural através da transferência de tecnologias. Neste sentido, com a Lei n. 6.126 , de 6 de novembro de 1974, foi iniciado um processo de estatização do Sistema Brasileiro de Extensão Rural e criada a Empresa Brasileira de Assistência Técnica e Extensão Rural (EMBRATER). No entanto, com o desmonte das estruturas de ATER na década de 1990, os serviços públicos de extensão rural no Brasil reduziram-se culminando na extinção da EMBRATER.

Durante muitos anos, especialmente por ocasião do processo de modernização da agricultura brasileira, as práticas de ATER foram caracterizadas 
difusionistas, onde a adoção e a introdução de tecnologias possuíam papel principal. Os agricultores eram meros depositários de conhecimentos e pacotes tecnológicos exógenos, sendo estes padronizados e muitas vezes inadequados às suas realidades, não considerando as reais necessidades dos agricultores. A partir dos anos 2000, retomaram-se as discussões em volta de uma nova ATER pública, sendo em 2003 foi instituída uma nova concepção de ATER que se sustenta até os dias atuais. A nova concepção vem agora da Política Nacional de Assistência Técnica e Extensão Rural (PNATER), que propõe um caráter mais extensionista com apelo à sustentabilidade no meio rural, e com ênfase em processos mais diversificados de desenvolvimento rural endógeno. Na concepção da PNATER são sugeridos a utilização de métodos mais participativos e tecnologia e conhecimentos na agricultura familiar baseados nos princípios da agroecologia, numa ação de ATER mais educativa e continuada com prática dialógica e uma pedagogia construtivista.

No novo contexto de ATER o técnico difusionista vai perdendo espaço para o técnico extensionista, onde este último passa a disponibilizar conhecimentos e técnicas no sentido de transformar a realidade dos atores, buscando melhorias nas condições de vida dos agricultores familiares. Para Caporal e Ramos (2006) os novos preceitos da extensão rural requer que o técnico extensionista esteja apto à utilização de técnicas e mecanismos participativos. Ao trocarem conhecimentos e saberes entre si, os técnicos e agricultores familiares poderão desenvolver novos conhecimentos que lhes permitirão escolher opções tecnológicas adequadas à demanda local. E é uma formação como esta, com conhecimentos direcionados à inovação no âmbito da agricultura familiar que a seleção de técnicos bolsistas do Instituto de Assistência Técnica e Extensão Rural (EMATER/RN) tem buscado para execução de políticas de desenvolvimento rural.

Diante do exposto, a questão central é: qual o perfil desejado para a formação dos bolsistas e quais os conhecimentos necessários para proporcionar a geração de inovação na agricultura familiar e para executar políticas para o desenvolvimento rural no Rio Grande do Norte? Como hipótese, o perfil de formação necessário para técnicos bolsistas da EMATER/RN vem constituir um quadro diversificado com profissionais de caráter extensionista, que se aproximem das demandas do agricultor familiar, atue de forma participativa e estimule processos endógenos de inovação na agricultura familiar. Neste sentido, o objetivo do artigo é analisar a formação e os conhecimentos necessários para a atuação dos técnicos bolsistas de ATER da EMATER, para promover a geração de inovação na agricultura familiar do Rio Grande do Norte pautada no desenvolvimento sustentável, visando melhores condições de vida para a população rural.

\section{REFERENCIAL TEÓRICO}

\subsection{Políticas públicas para a agricultura familiar e o desenvolvimento rural}

O já muito discutido conceito de desenvolvimento, em suas várias concepções, deve vir acompanhado de crescimento econômico, sendo o primeiro fruto do eficiente direcionamento de políticas que conseguem traduzir o segundo em níveis cada vez melhores de condições de vida para a população. Incrementos positivos no produto e na renda devem refletir em melhores indicadores de bem- 
estar, a exemplo da redução da pobreza, do desemprego, de desigualdades regionais, assim como de maior e melhor acesso a bons sistemas de saúde, de educação, alimentação e moradia mais dignas.

Essas constatações já foram lançadas por autores, a exemplo de Perroux (1967), e mais recente Sen (2000), no sentido de afirmar que o desenvolvimento não deve ser considerado apenas como o crescimento do Produto Nacional Bruto, limitado ao simples aumento de rendas pessoais, à industrialização ou avanços tecnológicos. Para estes autores, o desenvolvimento é resultado das capacidades humanas e deve também estar aliado a fatores não econômicos, a exemplo da organização coletiva, do acesso a bons serviços como saúde e educação, e maior participação em discussões públicas.

Essas afirmações se tornam válidas quando consideradas as ainda precárias condições de vida de populações no meio rural, especialmente em regiões como a do semiárido do Nordeste do Brasil, onde a agricultura familiar ainda se apresenta com infraestrutura e organização coletiva deficientes e sua produção pouca rentável. O meio rural é um ambiente desafiador, que desafia políticas no sentido gerar combinações que possibilitem aos agricultores familiares o acesso e disseminação de técnicas e de mecanismos que articulem os fundamentos da eficiência econômica, equidade social, territorial, ambiental, participação democrática. Para Schneider (2010), as políticas podem ser consideradas o conjunto de ações do estado e de instituições em intervenções nas regiões rurais pobres que não conseguem se integrar ao processo de modernização agrícola através da substituição de fatores de produção considerados atrasados.

Até o final dos anos 1980, conforme Miranda e Gomes (2016) surgiram técnicas difusionistas que defendiam a tese de que a pobreza no meio rural de países subdesenvolvidos se dava pela carência de tecnologias adequadas e pela falta e/ou deficiência de capital humano capacitado para a mudança tecnológica e de mentalidade. E a deficiência de capital humano se dava pela falta de investimentos em pesquisa, experimentação agrícola e educação rural, isso devido a não valorização das escolas rurais e da agricultura familiar pelas políticas nacionais (MIRANDA E GOMES, 2016, p. 78).

A partir da década de 1990, conforme Nunes et al (2015), transformações sociais, políticas e econômicas passaram a gerar uma nova discussão sobre o desenvolvimento rural e regional. Para Nunes et al (2015), essas transformações pressionaram o Estado no sentido da criação de políticas para reforma agrária, crédito para a agricultura familiar, para territórios rurais, e políticas para mulheres, jovens e negros. Miranda e Gomes (2016) argumentam que em um país como o Brasil marcado pela tradição latifundiária, o acesso a terra, ao crédito e ao mercado são fundamentais para o desenvolvimento rural e regional. A agricultura familiar ganhou reconhecimento a partir da constituição de 1988 onde novas relações foram estabelecidas entre o estado e a sociedade civil e novos mecanismos de política agrícola criados. O destaque foi a criação do Programa Nacional de Fortalecimento da Agricultura Familiar (PRONAF), em 1995, e do Ministério do Desenvolvimento Agrário, em 1999. (GRISA e SCHNEIDER, 2015). 


\subsection{A perspectiva do Capital Humano na análise}

A perspectiva do capital humano defende a ideia de que, indivíduos mais qualificados com maior nível de escolaridade alcançam melhores remunerações salariais, tornam-se mais produtivos e influenciam no crescimento econômico do país. A perspectiva está relacionada com habilidades naturais ou adquiridas pelos indivíduos através da aprendizagem, resultando em maiores retornos econômicos e sociais.

Para Andrade (2010, p.7), a discussão em torno do capital humano surgiu para explicar os ganhos de produtividade ocasionados pelo fator humano na produção, e o trabalho humano quando qualificado pelo fator educação, é uma das principais fontes de produtividade econômica e aumento das taxas de lucro. A educação passou a ser vista como um meio para se alcançar o desenvolvimento, e o trabalhador ao se tornar mais educado, estaria valorizando a si mesmo, como se valoriza o capital. Ao mesmo tempo em que o capital físico possui valor econômico, o capital humano também passa a possuir, pois, tornam-se fatores essenciais ao desenvolvimento. Ainda para Andrade (2010), países que apresentam crescimento constante na renda também apresentam aumento na educação e treinamento da sua força de trabalho.

Para Schultz (1973), muito daquilo a que se dá o nome de consumo constitui investimento em capital humano, e os gastos diretos com a educação, saúde, treinamentos no trabalho e com a migração interna para a consecução de vantagens oferecidas por melhores empregos, são exemplos claros. $O$ ensino médio e o ensino superior alcançaram um maior peso nas economias modernas porque 0 conhecimento e informações adicionais adquiridos com maior escolaridade são de extrema importância para as economias tecnologicamente avançadas. (ANDRADE, 2010, p.10)

Onde os homens sejam pessoas livres, o capital humano não é um ativo negociável, no sentido de que possa ser vendido. Pode, sem dúvida, ser adquirido, não como um elemento de ativo, que se adquire no mercado, mas por intermédio de um investimento no próprio indivíduo. Segue-se que nenhuma pessoa pode separar-se a si mesma do capital humano que possui. Tem de acompanhar, sempre, o seu capital humano, quer o sirva na produção ou no consumo. (SCHULTZ, p.53)

Mincer (1958) estudou a correlação entre o investimento na formação de pessoas (trabalhadores) e a distribuição da renda pessoal. Segundo o autor, era necessário decidir entre gastar tempo na obtenção de novos conhecimentos e aplica-los futuramente em atividades profissionais ou manter-se trabalhando sem a aquisição de novos conhecimentos. Com isso, Mincer (1958) conclui que, os rendimentos de um determinado indivíduo estariam associados a quantidade de investimento em capital humano dos quais impactariam na produtividade e no crescimento da economia.

Schultz (1973) defende a ideia de que, a capacidade produtiva dos seres humanos é muito maior do que todas as formas de riqueza tomadas em conjunto e, sendo assim, ao investirem em si mesmos, os indivíduos podem aumentar a disponibilidade de escolhas que estão à sua disposição. Sendo esta, uma das maneiras das quais os homens livres podem ampliar o seu bem-estar. Becker (1993) aponta que o capital humano é um conjunto de capacidades produtivas que uma 
pessoa pode adquirir com a acumulação de conhecimentos gerais ou específicos que podem, assim, serem utilizados na produção de riquezas. Dessa forma, segundo Viana e Lima (2010), os indivíduos optam por investir em educação considerando seus custos e benefícios.

\footnotetext{
Desse modo, o nível de capital humano de uma população influencia o sistema econômico de diversas formas, com o aumento da produtividade, dos lucros, do fornecimento de maiores conhecimentos e habilidades, e também por resolver problemas e superar dificuldades regionais, contribuindo com a sociedade de forma individual e coletiva. (VIANA e LIMA, 2010, p.139).
}

Viana e Lima (2010) abordam que uma das justificativas do crescimento desequilibrado é devido ao progresso desigual em determinadas áreas, tendo como exemplo o setor educacional. Com isso, o mesmo afirma que, uma das alternativas para diminuir as diferenças regionais seria investir em fatores que produzem resultados positivos ao crescimento econômico como o setor educacional, ou seja, capital humano.

Ao partir do pressuposto de que o capital humano, dimensionado pelo nível de educação, influencia significativamente no desempenho regional, considera-se que regiões que têm populações com maiores níveis de educação certamente terão maiores probabilidades de prosperidade. Em contrapartida, regiões com níveis inferiores tendem a ser mais estagnadas. Assim, o incentivo ao equilíbrio do capital humano entre as regiões diminui as disparidades econômico-regionais. (VIANA e LIMA, p.140).

Para Viana e Lima (2010), a educação pode ser considerada de duas formas: como consumo, pois em curto prazo, demanda gasto para sua execução e como investimento, devido à possibilidade de aumento nas rendas futuras dos estudantes tendo como resultado o crescimento econômico.

A perspectiva do capital humano considera também a influência da família na formação de conhecimentos, habilidades, valores e hábitos dos filhos. Para Becker (1993), a relação entre pais e filhos também pode interferir nos rendimentos. Corroborando, Andrade (2010) aponta que pais com maior poder aquisitivo conseguem pagar pela educação de seus filhos e mantê-los estudando ao invés de trabalhar; ao contrário de pais mais pobres que nem sempre alcançam essa oportunidade. Nesse contexto, a educação torna-se fator importante nas metodologias relacionadas à assistência técnica e extensão rural no Brasil visando tornar, muitas vezes pela indução, o agricultor familiar mais "moderno" e com capacidade organizacional e produtiva de gerar excedentes.

\subsection{Assistência Técnica e Extensão Rural no Brasil: breve histórico}

O início da extensão rural no Brasil está datado em meados de 1948 no estado de Minas Gerais, mas esta se originou nas universidades dos Estados Unidos e na Europa em meados do século XIX. Para Peixoto (2008), os conceitos de extensão rural evoluíram com o tempo e com a cultura de cada país podendo ser conceituado de três formas: como processo, instituição e política. 
Como processo, a extensão rural seria um meio de estender, levar ou transmitir conhecimentos de caráter educacional, sendo estes conhecimentos técnicos ou não, através de fontes geradoras (instituições púbicas, organizações e cooperativas), para o receptor final (o agricultor). Para Peixoto (2008), o conceito de extensão rural difere do conceito de assistência técnica, pois enquanto o primeiro possui caráter educativo, o segundo não visa à capacitação do agricultor, mas a resolução de problemas específicos. Segundo Peixoto (2008), a extensão rural como instituição refere-se às organizações governamentais as quais disponibilizam serviços de ATER nos estados a fim de promover desenvolvimento aos agricultores familiares. O conceito de extensão rural pode também ser entendido como política pública no tocante as políticas de extensão rural, desenvolvidas pelos governos federais, estaduais e municipais.

A expressão "extensão" surgiu em 1914 e se refere "a todos os meios e medidas para elevar o nível de vida rural", aproveitando "todos os ramos da ciência agrícola que se interessam pelo homem e a agricultura". Naquele ano, os Estados Unidos "institucionalizaram a Extensão Rural, com a finalidade de veicular entre a população rural conhecimentos úteis e práticos relacionados a agricultura, pecuária e economia doméstica" (FONSECA,1985 apud SCHMITZ, 2010, p.122 apud COSTA, 2014, p.25)

Para Freitas (1990), há um alto grau de concordância de que Extensão Rural é "a arte de interagir tecnicamente junto aos produtores rurais, a partir do conhecimento da realidade em todos os níveis, na incessante busca de combinar saber científico com saber popular, visando o aumento da produção". Ainda como processo, de acordo com Peixoto (2008), a extensão rural faz uso de métodos pedagógicos construídos e consagrados ao longo do tempo, os métodos tradicionais de ATER se dividem em:

\footnotetext{
Individuais: visita técnica, contato pessoal, unidade de observação (experimento na propriedade rural); 2. Grupais: reunião (palestra ou encontro, conferência), demonstração prática (de técnicas ou métodos), demonstração de resultados (de alguma inovação), unidade demonstrativa, curso, excursão, dia de campo, dia especial, propriedade demonstrativa; 3. De massa: exposição ou feira, semana especial, concurso, campanha (PEIXOTO, 2008).
}

Os serviços de ATER foram institucionalizados no Brasil na década de 1940 com a criação das Associações de Crédito e Assistência Rural (ACAR), no estado de Minas Gerais. A iniciativa surgiu de recomendações do empresário norte-americano Nelson Rockfeller para o governo de Minas, a fim de criar uma instituição que atuasse em favor da melhoria nas condições de vida no âmbito rural (CASTRO e PEREIRA, 2017, p.8).

A função desses institutos de pesquisa e extensão rural, segundo Castro e Pereira (2017) eram servir de interlocutor entre os agricultores e as instituições geradoras de inovação agropecuária. O modelo de extensão rural era caracterizado por ser desenvolvimentista, pois, introduzia relações capitalistas no meio de produção rural brasileiro. Dessa forma, os agricultores se vinculariam aos mercados de financiamento, insumos e comercialização. (CASTRO e PEREIRA, 2017, p.9). 
Com o surgimento da ACAR, várias outras instituições de assistência técnica e extensão foram surgindo em diversos estados do país, com base no modelo de ACAR implantado em Minas Gerais. De acordo com Castro e Pereira (2017), estas elaboravam projetos de desenvolvimento agrícola afim de que os produtores rurais conseguissem crédito rural subsidiado. O crédito veio do Sistema Nacional de Crédito Rural (SNCR), principal mecanismo de política agrícola de 1965 a 1986, criado pela lei 4.595 , de 31 de dezembro de 1964, tendo como principais agentes os bancos e cooperativas de crédito.

Ao final da década de 1950, os serviços de ATER já se encontravam presentes na metade dos estados brasileiros, estando presentes em todos os estados das regiões Sudeste e Sul e expandindo-se para os estados do Nordeste (Ceará, Pernambuco, Bahia, Rio Grande do Norte e Paraíba) e Centro-Oeste (Goiás). (OLIVEIRA, 1999 apud CASTRO e PEREIRA, 2017, p.9).

Com o crescimento da ACAR no território brasileiro, desencadeou-se a efetivação de um serviço de ATER no país: a Associação Brasileira de Crédito e Assistência Rural (ABCAR) em 1956. A ABCAR era de caráter privado, e reunia todas as ACARs seguindo um modelo centralizado e vertical de orientação. (CASTRO e PEREIRA, 2017, p.10).

Com a expansão dessas instituições, a Lei n. 6.126, de 6 de novembro de 1974 criou a Empresa Brasileira de Assistência Técnica e Extensão Rural (EMBRATER), substituindo a ABCAR, e as instituições estaduais de ATER, as ACARs, passaram a ser chamadas de Empresas Estaduais de Assistência Técnica e Extensão Rural (EMATER). De acordo com Castro e Pereira (2017), as EMATERs dependiam do auxílio financeiro da EMBRATER. Cabe ressaltar que dois anos antes, por meio da Lei 5.851, de 7 de dezembro de 1972 o governo brasileiro cria a Empresa Brasileira de Pesquisa Agropecuária (EMBRAPA), para ser responsável pela pesquisa e inovação agropecuária.

Por meio dessas mudanças, a EMBRATER se constituiu num poderoso instrumento de política agrícola, atuando de forma centralizada e vertical, por meio de uma prática alienante e domesticadora que visava disseminar a ideologia capitalista dominante para ampliar o processo de modernização das atividades agropecuárias e sua consequente subordinação aos complexos agroindustriais. (CASTRO E PEREIRA, 2017, p.10).

De acordo com Nunes et al. (2018), com a criação SNCR, em 1964, da EMBRAPA, em 1972, e da EMBRATER, em 1974, a estrutura pública institucional brasileira, inspirada no modelo norte-americano de ATER com base desenvolvimentista, se consolidou em meados de 1970. E foi essa estrutura que deu seguimento ao padrão agrícola do processo de modernização da agricultura brasileira. No entanto, com as duas crises do petróleo, em 1973 e 1979, e uma severa crise fiscal na década de 1980, fez com que o financiamento de quase todas os serviços estatais diminuísse. Com isso, a EMBRATER foi um dos órgãos que sofreram cortes orçamentários e reduziu sua capacidade de atuação, os mais afetados foram os estados e municípios mais pobres e os pequenos agricultores (CASTRO e PEREIRA, 2017, p.10). Dessa forma, em 1989, a então EMBRATER foi extinta. 
Com o fim da EMBRATER, a oferta de serviços de ATER por parte das instituições públicas reduziu-se drasticamente. Em meados dos anos 2000, as discussões sobre o desenvolvimento rural ressurgiram, e, com isso, em 2003 surgiu a Política de Assistência Técnica e Extensão Rural (PNATER), implantada pelo então Ministério do Desenvolvimento Agrário (MDA), ganhando força em 11 de janeiro de 2010 com a Lei $n^{\circ}$ 12.188. De acordo com Castro e Pereira (2017), o governo buscou mudar radicalmente o a ATER brasileira, reduzindo o difusionismo e ampliando o extensionismo por meio do desenvolvimento rural sustentável com foco nos atores marginalizados da modernização (agricultores familiares, quilombolas, indígenas, assentados...). E a política norteia as ações para a qualificação, inovação, reorganização e o fortalecimento da ATER brasileira.

Um dos princípios que norteiam o atual serviço da nova ATER pública é o desenvolvimento de processos educativos permanentes e continuados. Propõe romper o antigo difusionismo convencional estimulando o uso de métodos extensionistas mais participativos, a fim de contribuir para com o diálogo entre a educação tradicional e a científica. (CAPORAL, 2006 apud CASTRO e PEREIRA, 2017).

\begin{abstract}
De acordo com a PNATER, a Extensão Rural deve contribuir para a promoção do desenvolvimento rural sustentável, com ênfase em processos de desenvolvimento endógeno, adotando-se uma abordagem sistêmica e multidisciplinar mediante a utilização de métodos participativos e de um paradigma tecnológico baseado nos princípios da Agroecologia. Ao mesmo tempo, a PNATER sugere que se melhorem os processos de gestão social. Estabelece ainda que a nova ATER é um processo educativo, permanente e continuado, que se deve alicerçar em uma prática dialógica e em uma pedagogia construtivista. Essa Extensão Rural deve contribuir para uma melhor relação entre o urbano e o rural, para a melhoria da qualidade de vida, para o fortalecimento da cidadania e para a produção de alimentos limpos. (CAPORAL e RAMOS, 2006, p.3)
\end{abstract}

Para Caporal e Ramos (2006), os novos serviços de ATER são contrários às práticas históricas da extensão rural que tinha sua base na difusão de inovações tecnológicas e levavam os extensionistas a atuarem como transferidores de tecnologia. Os agricultores familiares eram colocados como meros depositários de conhecimento e pacotes gerados "de fora" pela pesquisa, muitas vezes inadequados as suas realidades e condições.

Por trás desse tipo de Extensão Rural, que foi dominante ao longo de várias décadas, estava um modelo de desenvolvimento urbano-industrial cuja viabilização necessitava que a agricultura cumprisse funções, entre as quais a de fornecedora de mão-de-obra e de consumidora de serviços e produtos industrializados, como as máquinas, os equipamentos, as sementes híbridas ou melhoradas, os agrotóxicos e fertilizantes químicos sintéticos, além de contribuir, pelas exportações, para o superávit da balança comercial. Esse modelo, que é fruto de decisões políticas, norteou a ação extensionista. Ao mesmo tempo, continua sendo responsável pela concentração da terra, pelo êxodo rural, pela baixa escolaridade no campo, pela redução da biodiversidade, pela poluição, pela contaminação dos alimentos, pela exclusão social, pela desvalorização do trabalho na agricultura, pelo empobrecimento no meio rural, entre outros problemas. (CAPORAL e RAMOS, 2016, p.3). 
Diante desse contexto, Paulo Freire (1983, apud CAPORAL e RAMOS, 2006), destacou como princípio crítico do processo educacional e da extensão convencional propondo uma relação dialética entre o agricultor e o extensionista, para a construção de conhecimentos adequados a cada realidade e a troca de saberes como valorização da cultura local. Segundo Caporal e Ramos (2016), as ações extensionistas não devem estar centradas na assistência técnica individual, mas envolver comunidades e grupos:

É preciso, por exemplo, identificar jovens rurais e agricultores que possam ser qualificados para ajudar os demais a resolver problemas simples de manejo agropecuário, estimular os mutirões e fortalecer o intercâmbio de conhecimentos entre famílias de agricultores, promover estágios de agricultores em propriedades, realizar pesquisa participativa e estimular o estabelecimento de interações que possibilitem a disponibilização e a socialização de saberes na relação agricultor vs agricultor.

O agente de ATER, além de assessor técnico, deve ser a de mediador de processos de desenvolvimento, possuir formação técnica diversificada (agronômica, econômica, florestal, veterinária, sociológica, etc.) e acrescentar outros conhecimentos no seu aprendizado para desenvolver seu trabalho com qualidade. (CAPORAL e RAMOS, 2006).

Os serviços de Assistência Técnica e Extensão Rural (ATER) no Rio Grande do Norte surgiram, de acordo com a EMATER (2016), em 27 de julho de 1955, através da Associação Nordestina de Crédito e Assistência Rural (ANCAR), em quatro municípios: Santa Cruz, São Tomé, São Paulo do Potengi e Currais Novos. A instituição era coordenada pela ANCAR regional situada em Recife-PE, cujo objetivo era promover o desenvolvimento socioeconômico do homem no campo que em 2015 completou seis décadas de ação no estado (EMATER, 2016).

As ações de ATER, segundo a EMATER (2016), possuíam caráter difusionista e educativo para o credito rural supervisionado, buscando a introdução de tecnologias externas para o melhoramento na produção, aumento da produtividade e melhor aproveitamento das riquezas naturais. As orientações desenvolvidas pelos técnicos eram direcionadas as culturas e criações, como também a constituição de casas de farinha, armazéns, currais, etc. para o desenvolvimento agropecuário, cuidados com os alimentos, vestuário e administração do lar. (EMATER, 2016).

No ano de 1958, foi instituído o convênio da ANCAR com o governo do estado, para facilitar o trabalho desenvolvido no Rio Grande do Norte, que até então eram coordenados à distância pela ANCAR regional em Recife (EMATER, 2016). Em meados de 1956, o serviço de extensão no Rio Grande do Norte já possuía 10 escritórios locais, 14 técnicos e 16 funcionários administrativos, coordenados estes pela Associação Brasileira de Crédito e Assistência Rural (ABCAR). (EMATER, 2016).

De acordo com a (EMATER, 2016), as ações de ATER no Rio Grande do Norte tinham como lema "ajudar o homem a ajudar a si mesmo", com a finalidade de desenvolver um trabalho cooperativo com base em princípios educacionais. Buscava-se o aprendizado na agricultura e pecuária (ação técnica de produção econômica) e economia doméstica (ação social). Os atores envolvidos eram lideranças, grupos de produtores, atividades com jovens do meio rural através dos 
clubes designados " $4 \mathrm{~S}$ " que significava saber, sentir, saúde e servir, e mini postos de saúde que contribuíram para o desenvolvimento das comunidades rurais. Com a substituição da ANCAR pela EMATER-RN, esta última criada pela lei estadual $n^{\circ}$ 4.484/75, ficou vinculada à Secretaria Estadual de Agricultura-SAG. Nesse novo arranjo, foram criadas diretrizes e estratégias estaduais de acordo com as políticas agrícolas do governo federal, dando ênfase a transferências de tecnologia agropecuária e gerencial para agricultores e cooperativas. (EMATER, 2016).

Segundo a EMATER (2016), após a extinção da EMBRATER, os recursos financeiros diminuíram e a EMATER-RN tornou-se inviável, colocada como incapaz de continuar a realizar convênios, contratos, acordos e impossibilitada de vender seus serviços. Em 05 de outubro de 1993, a lei nº 6.486 passou a chamar a EMATERRN de Instituto de Assistência e Extensão Rural do Rio Grande do Norte (INATERN), vinculada à Secretaria de Estado da Agricultura, da Pecuária e da Pesca (EMATER, 2016).

A atribuição do INATERN é a de planejar e executar serviços de ATER no Rio Grande do Norte, nas atividades de agricultura, pecuária, agroindústria e atividades não agrícolas, tendo como finalidade orientar e avaliar projetos de crédito rural, preservação e recuperação do meio ambiente e na capacitação técnica dos agricultores familiares. Em 02 de fevereiro de 1995, o INATERN voltou a chamar-se EMATER, tornando-se até os dias atuais pela lei complementar $n^{\circ}$ 129. (EMATER, 2016).

Conforme Grisa \& Schneider (2015), a partir dos anos 1990 o PRONAF (criado em 1995, com caráter de uma política com foco na oferta) dá partida para a construção de medidas visando afirmar ainda mais a agricultura familiar, e resgata a Assistência Técnica e Extensão Rural (ATER) pública. Para Grisa \& Schneider (2015), a criação do Seguro da Agricultura Familiar (SEAF), em 2004, e do Programa de Garantia de Preço da Agricultura Familiar (PGPAF), em 2006, atrelavam ações de ATER a estes mecanismos de política.

Mais recentemente, a partir de 2003, conforme Nunes et al. (2018), técnicos de EMATERs no Brasil têm desempenhado importante papel extensionista na geração de conhecimentos e inovação. A ação se dá na construção de mercados para a agricultura familiar, capacitando extensionistas e agricultores para a execução de políticas com foco na demanda: o Programa Nacional de Alimentação Escolar (PNAE) e o Programa de Aquisição de Alimentos (PAA). Para Nunes et al. (2018), a integração com as ações de ATER representa valioso suporte aos agricultores familiares e suas organizações no acesso às políticas, bem como planejar a produção e a logística para a comercialização.

\section{PROCEDIMENTOS METODOLÓGICOS}

O ambiente da pesquisa é o estado do Rio Grande do Norte, situado na região Nordeste do Brasil que, segundo dados do Instituto Brasileiro de Geografia e Estatística - IBGE (2017), é composto por 167 municípios numa área territorial de $52.107 \mathrm{~km}^{2}$, e, segundo o Censo de 2010, possui uma população de 3.479 .010 habitantes.

A unidade de análise é o técnico/bolsista da EMATER selecionado por meio do edital $n^{\circ}$ 002/2016, que tem sua formação específica e atua a partir de 
conhecimentos diversificados na agricultura familiar de cada uma das dez regionais da EMATER do Rio Grande do Norte, conforme figura 1: Mossoró, Assú, João Câmara, Pau dos Ferros, Umarizal, Caicó, Currais Novos, Santa Cruz, São Paulo do Potengi e São José de Mipibu.

Figura 1 - Mapa do Rio Grande do Norte com as regionais da EMATER

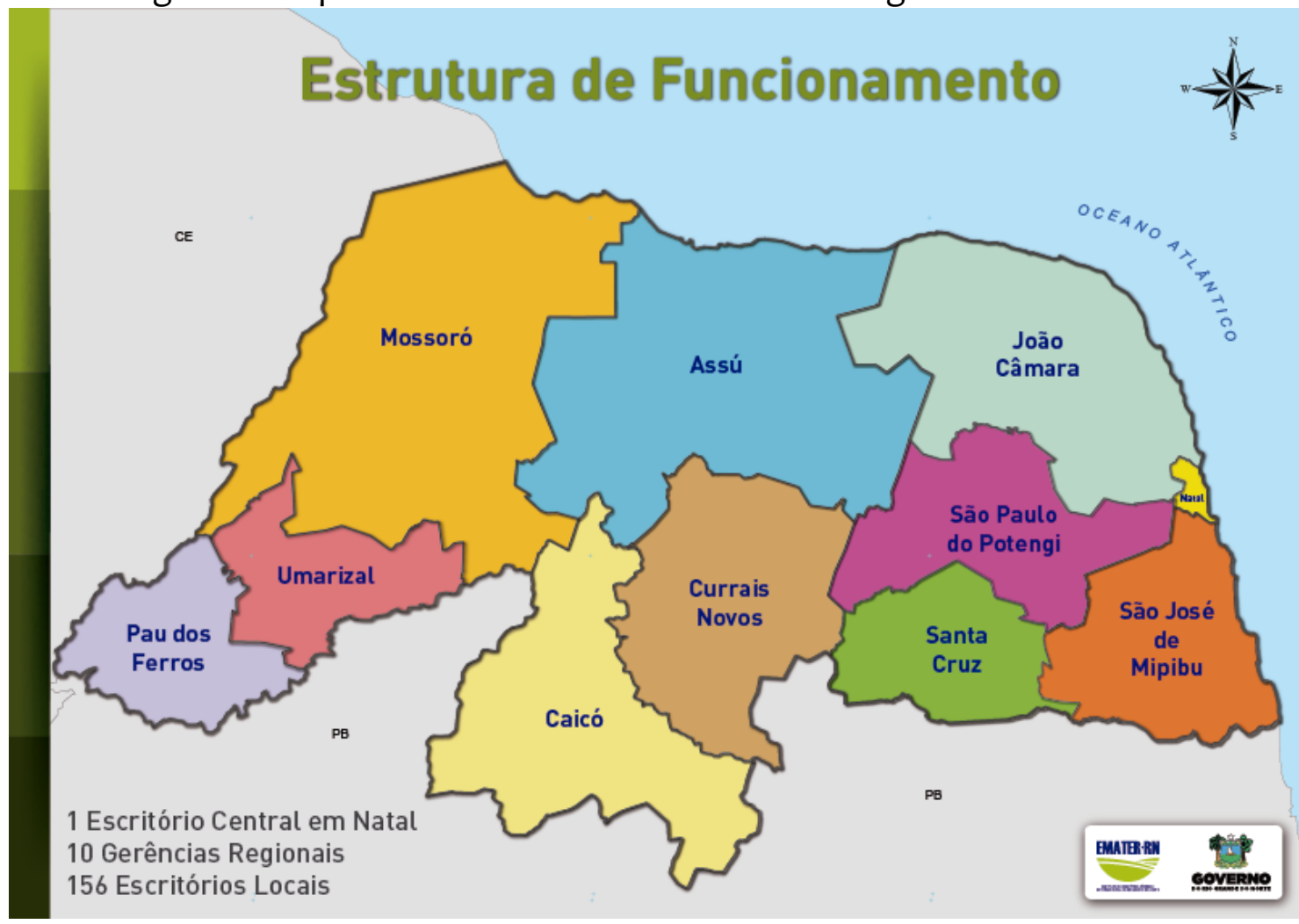

Fonte: EMATER/RN, 2018.

O universo aqui é constituído por 135 bolsistas/extensionistas que compõem as 10 regionais da EMATER do Rio Grande do Norte, com formação técnica de nível médio, tecnólogo e nível superior em diversas áreas, sendo que, apenas 67 responderam o questionário, e os demais não justificaram. Dos 67 entrevistados, 34 são homens e 33 são mulheres, conforme distribuição por regional: 7 de Assú, 7 de Mossoró, 5 de São Paulo do Potengi, 9 de João Câmara, 3 de Santa Cruz, 3 de São José do Mipibu, 4 de Umarizal, 22 de Natal, 3 de Currais Novos e 4 Pau dos Ferros. A figura 2 mostra os municípios que recebem as ações de ATER, e que compõem cada regional da EMATER no estado. 
Figura 2 - Regionais da EMATER/RN e as respectivas cidades que as compõem

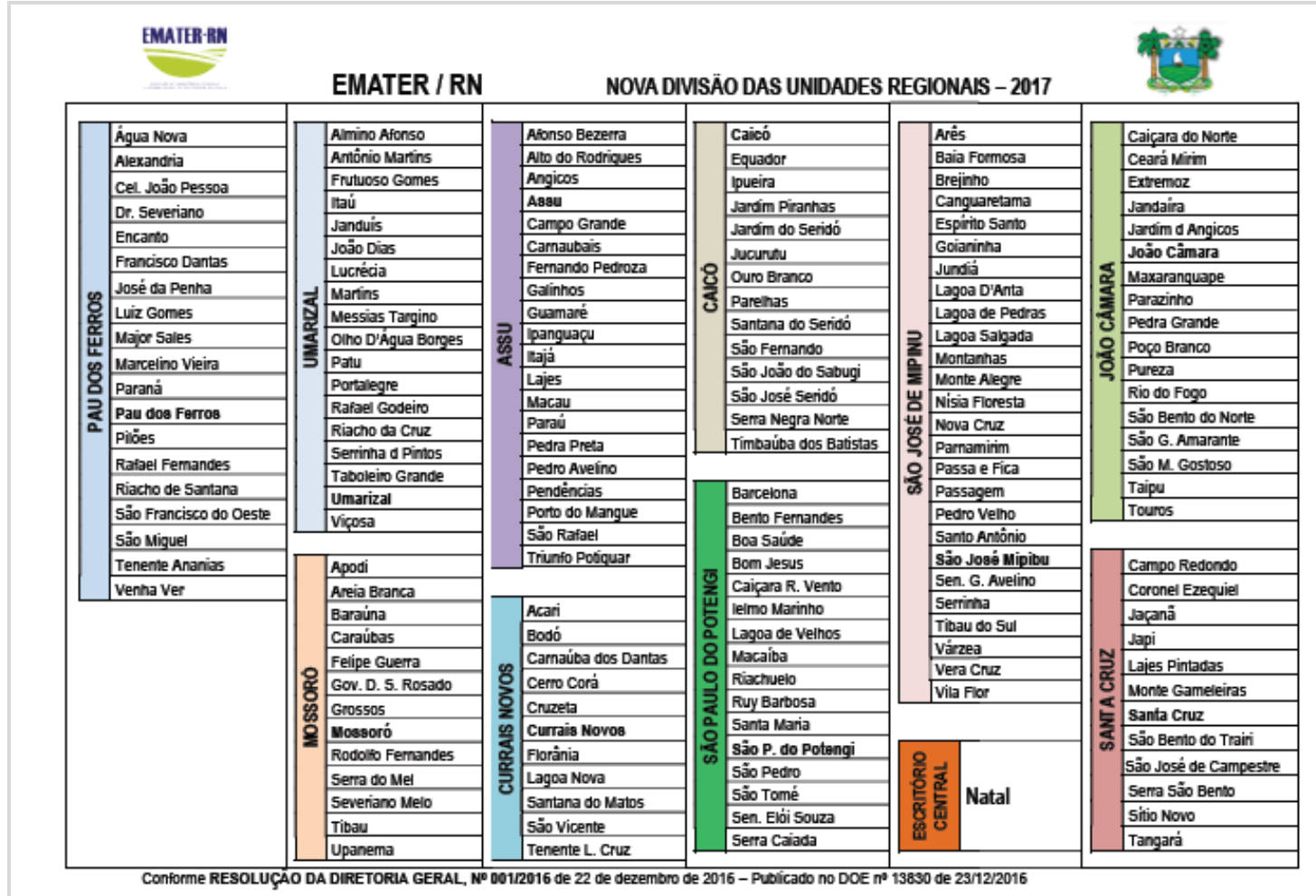

Fonte: EMATER/RN, 2018.

Os dados consistiram em primários e secundários. Os primários foram coletados a partir de um questionário via formulário do Google (composto por 10 perguntas) aplicado a 135 bolsistas/extensionistas da EMATER-RN, no período de março a junho de 2018; e os dados secundários foram por meio da tabulação e à análise dos mesmos a fim de responder os objetivos da pesquisa.

A pesquisa caracteriza-se por ser exploratória, pois se baseou em levantamentos bibliográficos e na aplicação de questionários estruturados. Segundo Gil (2008, p. 27), a pesquisa exploratória tem por objetivo, desenvolver, esclarecer e modificar conceitos e ideias visando a formulação de problemas mais precisos ou hipóteses para estudos futuros. As que envolvem levantamento bibliográfico e documental, entrevistas e estudos de caso e técnicas quantitativas, não são aplicadas neste tipo. (GIL, 2008, p. 27).

Quanto à abordagem, utilizou-se da pesquisa descritiva, pois, buscou-se descrever as características de uma população específica. Para Gil (2008, p.27), o objetivo deste tipo de pesquisa se caracteriza por descrever as características de determinada população ou fenômeno ou o estabelecimento de relações entre variáveis. Ainda para o autor, outra característica da pesquisa descritiva é o levantamento de opiniões, atitudes e crenças de uma dada população. E da qualitativa, pois, as informações alcançadas não são quantificáveis, mas, descritivas e os dados são analisados indutivamente, e do método utilizou-se a abordagem analítico-descritiva, pois procurou analisar e explicar a partir das informações disponíveis e descrever com base nas respostas obtidas da aplicação do questionário os objetivos a serem alcançados. 


\section{RESULTADOS E DISCUSSÃO}

\subsection{A formação e os conhecimentos de ATER para a inovação da agricultura familiar e o desenvolvimento rural no Rio Grande do Norte}

Uma das concepções que fundamentam as atuais ações de ATER pública no Rio Grande do Norte é a de oferecer um acompanhamento técnico continuado, focado nas demandas dos agricultores familiares e de suas organizações coletivas. Neste sentido, no âmbito da EMATER, é demonstrada a preocupação com a formação dos seus técnicos, onde a Agência Nacional de Assistência Técnica e Extensão Rural (ANATER) tem desenvolvido no Rio Grande do Norte uma proposta de formação pública continuada. A metodologia busca o caráter extensionista na qualificação dos técnicos/bolsistas da EMATER (na concepção da PNATER), utilizando métodos mais participativos para trabalhar temas diversificados, a exemplo da agroecologia, atividades não-agrícolas, avicultura, agroindústria familiar, bovinocultura, ovinocaprinocultura, comercialização da produção, organização de bancos de sementes, piscicultura, etc. O propósito é o de direcionar as ações de ATER a partir de conhecimentos capazes de engendrar processos de diversificação da agricultura familiar potiguar com inovação e inclusão, com vistas a melhorar o acesso a políticas públicas e gerar oportunidades de construção de mercados.

Quanto às ações de ATER pública, uma demonstração da ação dos técnicos extensionistas reside na distribuição do número de atendimentos e do número de famílias de agricultores familiares atendidas. Considerando o somatório das regionais da EMATER em todo o Rio Grande do Norte no período de 2011 a 2018, foram registrados: 8.863 atendimentos em 2011, baixando um pouco para 5.515 no ano de 2012, e aumentando significativamente nos anos de 2013, 2014 e 2015 com 23.218, 28.942 e 32.496, respectivamente. A partir do ano de 2016 o número de atendimentos cai drasticamente para 19.407 atendimentos em 2016, sendo registrados 10.436 em 2017 e para apenas 1.597 no ano de 2018, conforme mostra a figura 3.

Figura 3 - Número de atendimentos de ATER no Rio Grande do Norte, de 2011 a 2018

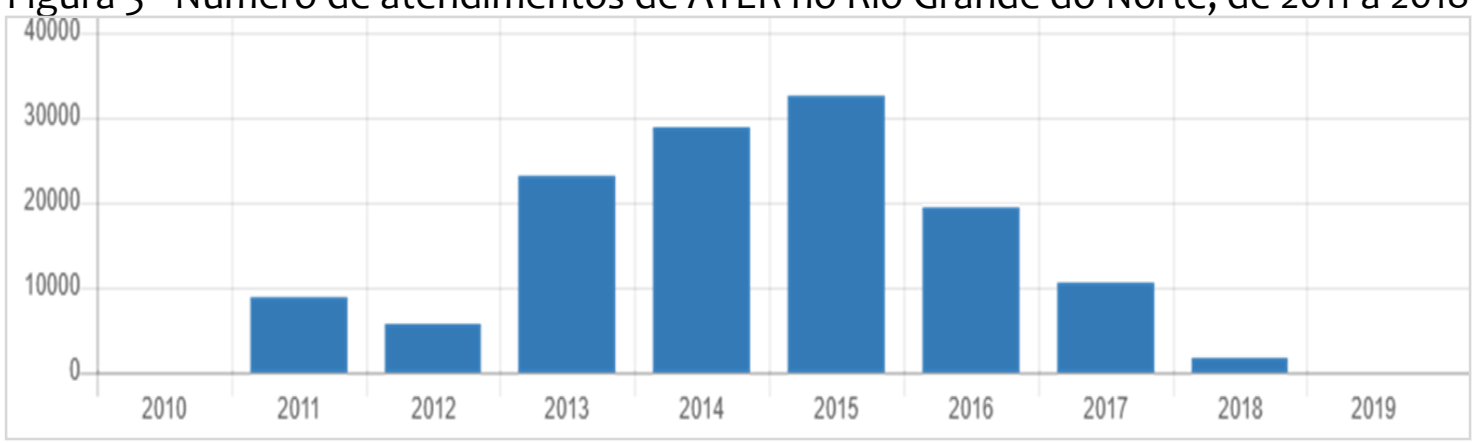

Fonte: Painel de Monitoramento de Políticas da SEAD, 2019.

Quanto ao número de famílias atendidas, foram registradas 2.244 famílias em 2011, aumentando para 3.058 em 2012, e tendo um salto considerável nos anos de 2013 e 2014 com 7.080 e 9.309 famílias atendidas, respectivamente. No entanto, nos anos seguintes o número de famílias atendidas cai para 8.126 em 2015, para 5.806 
em 2016, depois 2.196 em 2017, e para apenas 642 famílias atendidas no ano de 2018, conforme mostra a figura 4.

Figura 4: Número de famílias atendidas por ATER no Rio Grande do Norte de 2011 a 2018

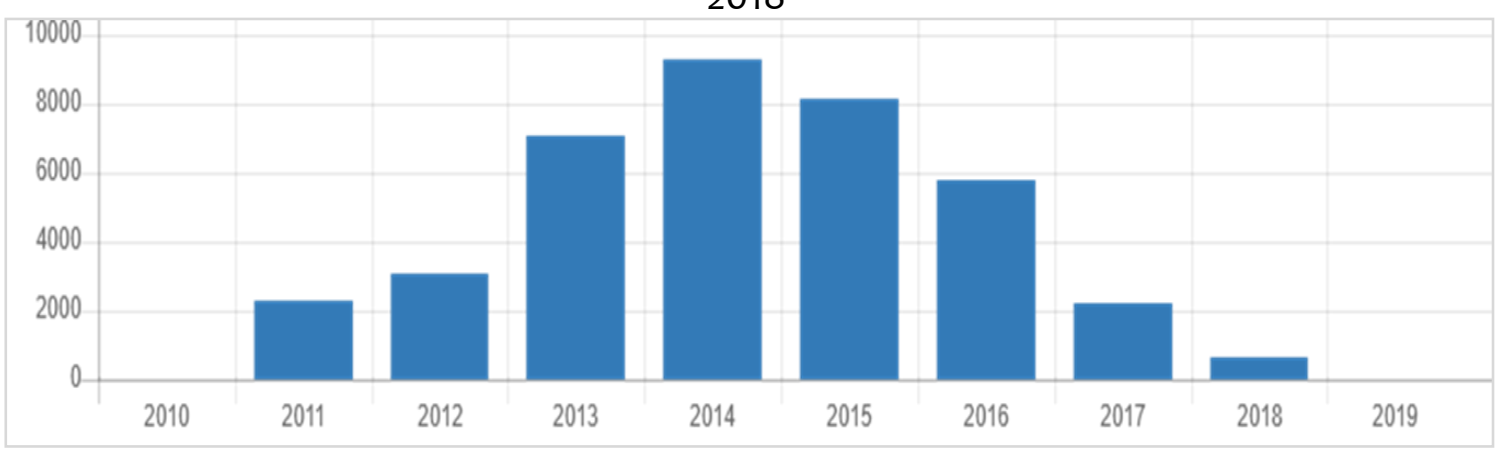

Fonte: Painel de Monitoramento de Políticas da SEAD, 2019.

Comparando as duas figuras acima, uma característica comum entre elas é o auge e o declínio de 2011 a 2018, tanto do número de atendimentos de ATER como de famílias atendidas. No entanto, na primeira é notada uma evolução do número de atendimentos até o ano de 2015 com forte declínio em 2016, expressando uma diferença com a segunda que tem o auge do número de famílias atendidas um ano antes, em 2014, assim como antecipando para o ano de 2015 o seu declínio. Esse auge e declínio das ações de ATER revelam fragilidade na descontinuidade e na instabilidade de políticas que deveriam estimular o desenvolvimento rural por meio das ações contínuas de ATER. Na verdade, a descontinuidade é comum de regiões que apresentam muita desigualdade, e acaba sendo um dos fatores limitantes e grande desafio para elevar o nível de competividade, pois a falta de incentivos e a duração limitada de tempo para capacitar os agricultores familiares tendem a tornar esses programas paliativos e pouco eficientes.

Quando analisados os números de atendimentos e de famílias atendidas de agricultores familiares, considerando cada uma das regionais da EMATER, fica expressa a desigualdade dos registros de ATER no Rio Grande do Norte. Como mostra o gráfico 1, as ações de ATER encontram-se concentradas em quatro das dez regionais da EMATER, ou seja, nas regionais de João Câmara com 33.177 atendimentos, seguida da regional de Pau dos Ferros, Mossoró e Umarizal, com 26.900, 23.098 e 14.462 registros, respectivamente. 
Gráfico 1 - Número de atendimentos e de famílias atendidas por Regional da EMATER-RN (2011 a 2018)

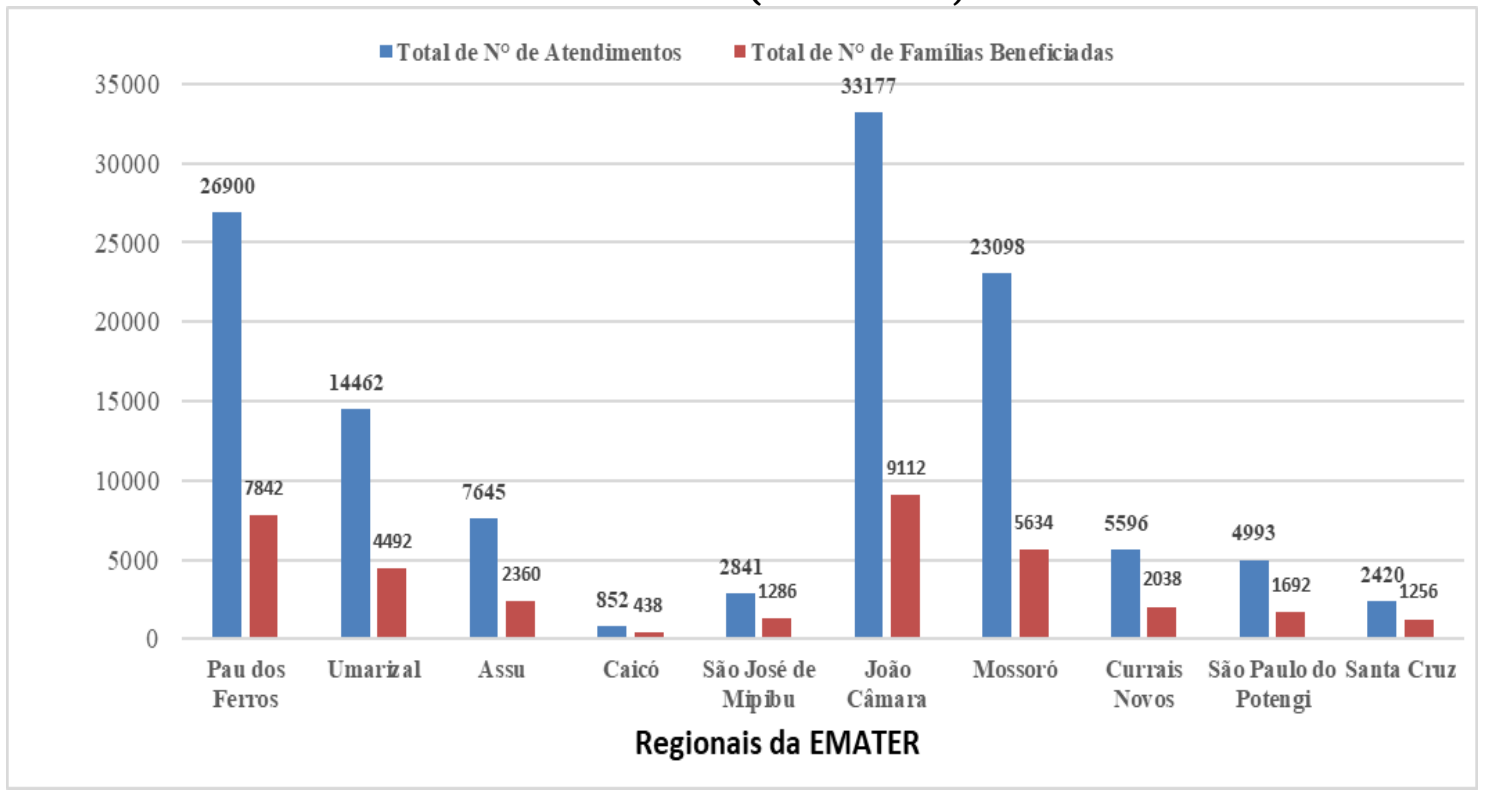

Fonte: Painel de Monitoramento de Políticas das SEAD, 2019. Elaboração dos autores.

Quanto a formação e os conhecimentos necessários para gerar inovação no âmbito da agricultura familiar, o direcionamento é o de afirmar no âmbito da EMATER o caráter extensionista, visando executar políticas e engendrar processos diversificados de desenvolvimento rural. De início, procurou analisar quais os requisitos e o grau de formação necessário para a sua atuação; e em um segundo momento, foram observados conhecimentos necessários para o desenvolvimento das atividades como extensionistas.

No que diz respeito ao perfil de formação necessário para a seleção dos bolsistas/extensionistas da EMATER-RN, descrito no edital $n^{\circ}$ 002/2016 para a execução das tarefas durante 24 meses, foram considerados fatores como a experiência profissional, perfil de formação e critérios descritos no quadro 1. 
Quadro 1 - Perfil do selecionado: ter experiência profissional, estar nas categorias e atender aos critérios EXPERIÊNCIA PROFISSIONAL

Exercício de atividade profissional na área pretendida, na Administração Pública, Privada ou Organizações Sociais, que exclusivamente atuem, comprovadamente, no seguimento de Assistência Técnica e Extensão Rural - ATER.

Exercício de atividade profissional na área pretendida, na Administração Pública, Privada ou Organizações Sociais, que não atuem no seguimento de Assistência Técnica e Extensão Rural - ATER.

Estágio curricular obrigatório ou não obrigatório na área pretendida, na Administração Pública, Privada ou Organizações Sociais, que exclusivamente atuem, comprovadamente, no seguimento de Assistência Técnica e Extensão Rural - ATER.

Estágio curricular obrigatório ou não obrigatório na área pretendida, na Administração Pública, Privada ou Organizações Sociais, que não atuem no seguimento de Assistência Técnica e Extensão Rural - ATER.

Trabalhos científicos e artigos apresentados em congressos ou simpósios, publicações em periódicos, ou orientação e co-orientação de trabalhos, relacionados à área pretendida nos últimos 3 anos, até o limite de 5 trabalhos.

Ministrar e ou participar de cursos, congressos, palestras, simpósios, jornadas, oficinas e outras atividades correlatas a área pretendida de no mínimo 8 horas nos últimos 3 anos, até o limite de 5 participações.

CATEGORIA PROFISSSIONAL

Auxiliar Administrativo

Técnico Agrícola (Agropecuária ou

Agroecologia)

Técnico em Informática

Bacharel em Direito

Administrador

Arquiteto

Assistente Social

Biblioteconomista

Contador

Educador Físico

Médico Veterinário

Engenheiro Civil

Engenheiro de Pesca

Nutricionista

Publicitário

Jornalista

Secretariado Executivo

Analista de Sistema

Estatístico

\section{REQUISITOS ESPECÍFICOS}

Ensino médio completo, ter curso em informática: Word, Excel, Power Point.

Ensino Médio Técnico na área, registro no CREA e Carteira Nacional de Habilitação

Ensino Médio Técnico na área ou experiência comprovada de no mínimo 2 anos e Carteira Nacional de Habilitação Ter curso superior em Direito.

Ter curso superior em Administração e registro no CRA.

Ter curso superior de Arquitetura e Urbanismo, registro no CAU e Carteira Nacional de Habilitação.

Ter curso superior em Serviço Social, registro no CRESS e Carteira Nacional de Habilitação.

Ter curso superior em Biblioteconomia, registro no CRB

Ter curso superior em Contabilidade, registro no CRCN e Carteira Nacional de Habilitação.

Ter curso superior em Educação Física, registro no CREF e Carteira Nacional de Habilitação

Ter curso superior em Medicina Veterinária, registro no CRMV e Carteira Nacional de Habilitação.

Ter curso superior em Engenheira Civil, registro no CREA e Carteira Nacional de Habilitação.

Ter curso superior em Engenharia de Pesca com registro no CREA e Carteira Nacional de Habilitação

Ter curso superior em Nutrição, registro no CRN e Carteira Nacional de Habilitação

Ter curso superior e comunicação social - Habilitação em Publicidade e Propaganda

Ter curso superior e comunicação social - Habilitação em Jornalismo

Ter curso superior em Secretariado Executivo.

Ter curso superior em Sistemas de Informação

Ter curso superior em Estatística e registro no CONRE.

\section{CRITÉRIOS}

Atuação em atividades de pesquisa correlatas à área do profissional;

Conhecimento acerca das atividades e competências da EMATER/RN;

Conhecimento das atividades a qual se candidata;

Avaliação de habilidades que serão úteis ao desempenho das atividades;

Desenvolver trabalho em equipe;

Apresentar boa capacidade de comunicação;

Ter iniciativa; e

Capacidade de articulação.

Aspectos Interpessoais

Fonte: FUNCITERN/EMATER/RN. Elaborado pelos autores com base no edital n002/016.

Com base nas formações necessárias descritas no quadro acima para a atuação dos extensionistas nos serviços de ATER, ao comparar com as informações 
extraídas da aplicação do questionário, a pesquisa revelou que os selecionados possuiem formação em nível técnico médio, tecnólogo ou nível superior. Neste sentido, a maioria dos selecionados possui nível médio, ou seja, $48 \%$ dos profissionais com formação técnica, $6 \%$ com formação tecnóloga e $46 \%$ com ensino superior completo, como mostra o gráfico 2.

Gráfico 2 - Graus de formação dos extensionistas

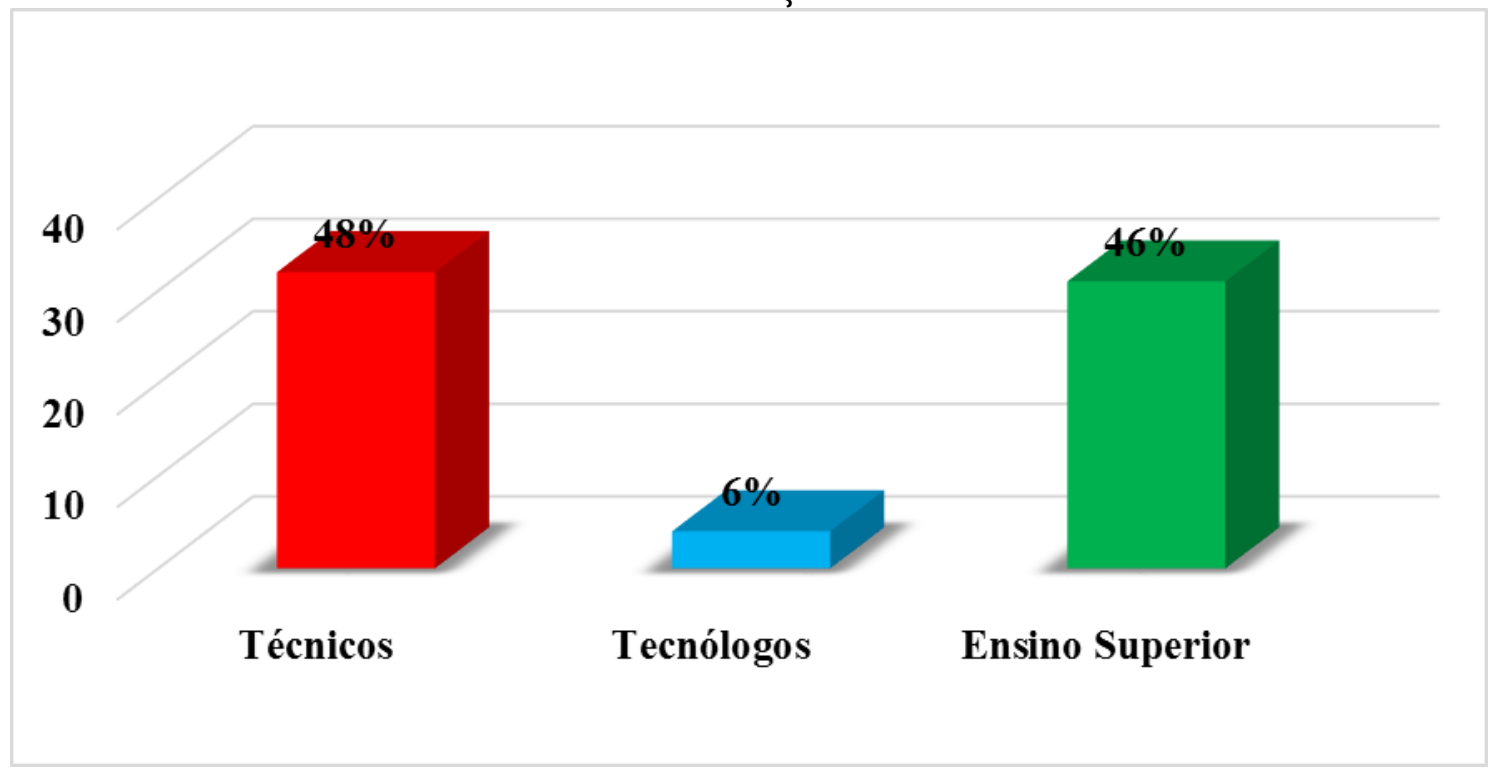

Fonte: Elaboração dos autores a partir de EMATER-RN (2016).

A pesquisa revelou que os profissionais possuem formações diversificadas, não predominantemente nas ciências agrárias. Ao contrário do caráter difusionista que sempre priorizou a centralidade nas ciências agrárias e os serviços de ATER estarem direcionados para o ambiente da agropecuária, o interesse foi para obter um profissional com caráter mais extensionista. Por buscar a aplicação de métodos na utilização de temas relacionados a geração de conhecimentos no sentido de engendrar processos de desenvolvimento rural valorizando a diversificação e inovação da agricultura familiar, é que mostra a necessidade de profissionais de áreas diversificadas do conhecimento, conforme gráfico 2. E esse é um desafio, pois se insiste na concepção de ATER em que a inovação se traduza em inclusão de famílias de agricultores via construção de mercados. 
Gráfico 3 - Formação dos Extensionistas e Respectivas Quantidades

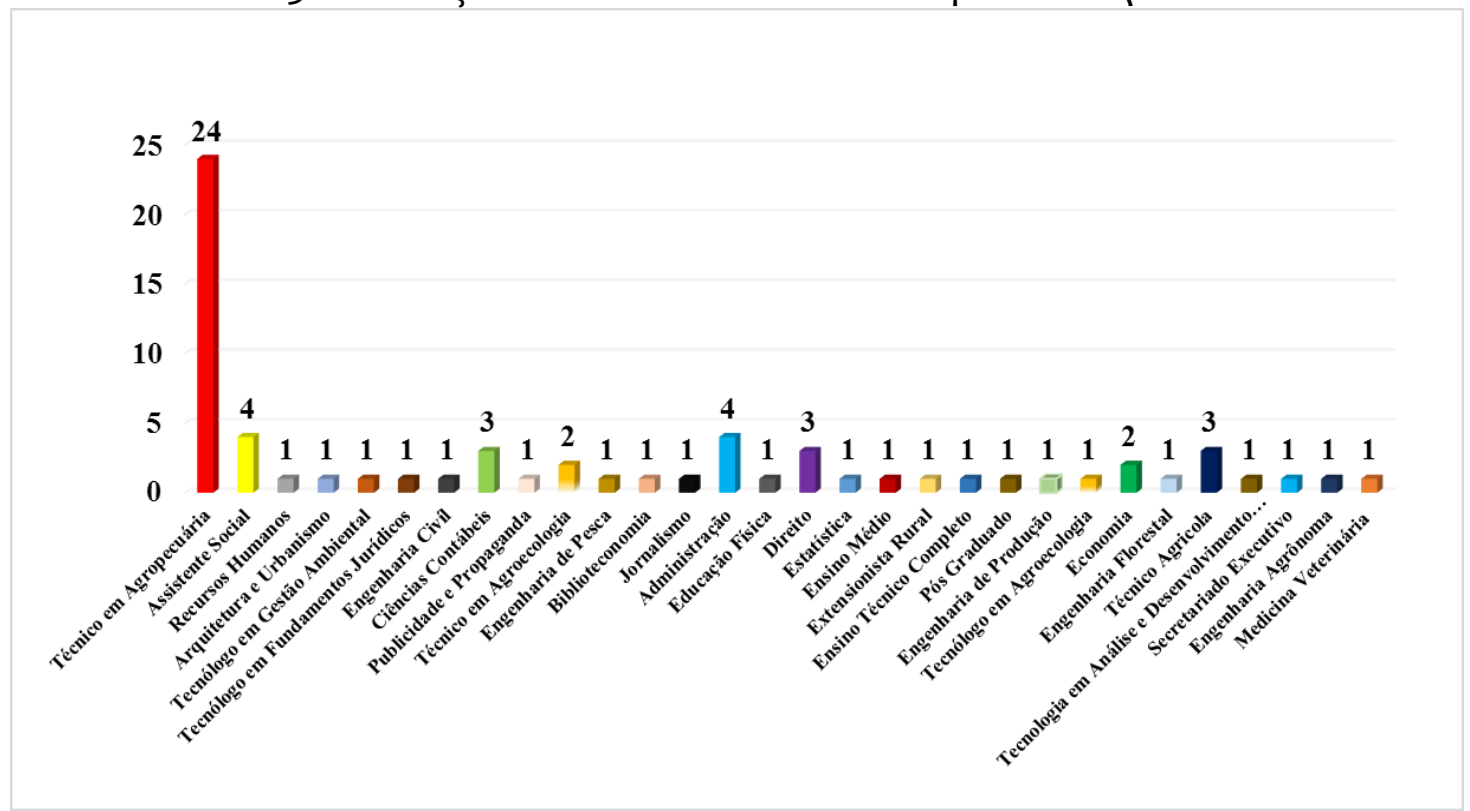

Fonte: Elaboração dos autores a partir de EMATER-RN (2016).

As áreas da ciência social são: Assistência Social, Recursos Humanos, Arquitetura e Urbanismo, Tecnólogo em Fundamentos Jurídicos, Engenharia Civil, Ciência Contábeis, Publicidade de Propaganda, Biblioteconomia, Jornalismo, Administração, Educação Física, Direito, Estatística, Engenheiro de Produção, Economia, Tecnologia em Análise e Desenvolvimento de Sistemas (TADS), Secretariado Executivo. As áreas das ciências agrárias são: Técnico em Agropecuária, Tecnólogo em Agroecologia, Engenharia Florestal, Técnico Agrícola, Engenharia Agrônoma, Medicina Veterinária.

Como já abordado por Caporal e Ramos (2006, p. 10), o agente de ATER além de assessor técnico, deve ser também mediador de processos endógenos de desenvolvimento regional-rural. Deve possuir formação técnica diversificada e deve acrescentar aos seus conhecimentos, conhecimentos de outras áreas, a fim de, desenvolver seu trabalho com qualidade. (CAPORAL e RAMOS, 2006, p.10).

Quanto aos conhecimentos mais mencionados pelos bolsistas/extensionistas da EMATER/RN, quando questionados sobre quais conhecimentos seriam necessários para que eles executassem suas atividades, no sentido de gerar inovação e diversificação na agricultura familiar do Rio Grande do Norte, as respostas são mostradas no gráfico 4 .

Com base nas respostas dos 67 extensionistas, os conhecimentos mais mencionados os sobre a própria atividade de Assistência Técnica e Extensão Rural e políticas desenvolvidas pela EMATER/RN, com 27\%, conhecimentos sobre informática e administrativos, com $27 \%$, conhecimentos práticos e teóricos, com $22 \%$, conhecimentos sobre o local em que atuam, com 16\%, e os conhecimentos que já possuíam, com $8 \%$. 
Gráfico 4 - Conhecimentos Mencionados

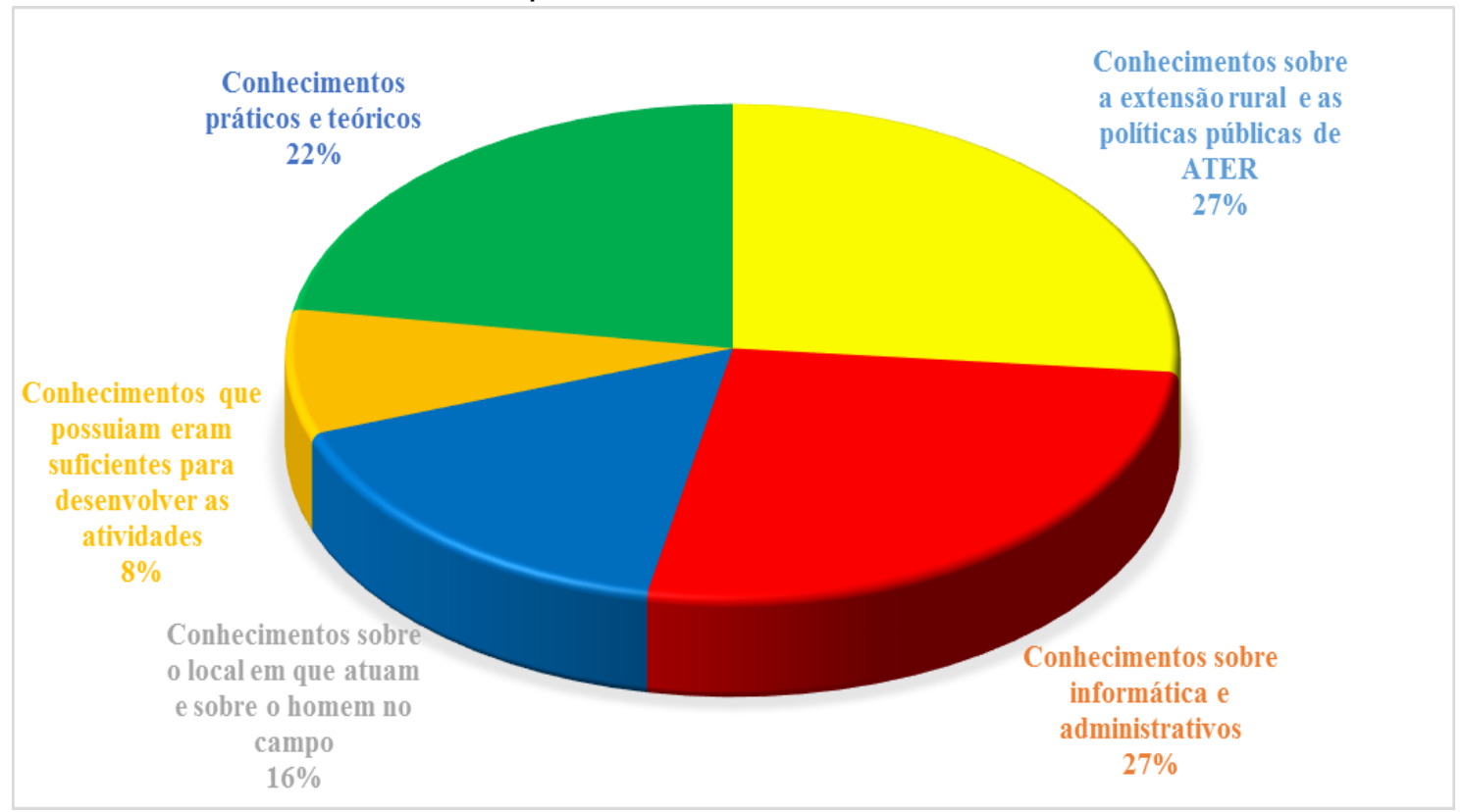

Fonte: Elaboração dos autores a partir de EMATER-RN (2016).

Os conhecimentos teóricos e práticos sobre agricultura, pecuária e meio ambiente foram mencionados oito vezes pelos entrevistados, mostrando interesse na geração de inovação da agricultura familiar. Os conhecimentos que já possuíam serem suficientes para as atividades, assim como os conhecimentos práticos e teóricos acerca da própria atividade de ATER, foram mencionados quatro e onze vezes, respectivamente. E os conhecimentos sobre informática e administrativos foram mencionados 13 vezes; e os sobre o local em que atuam e sobre o homem do campo foram mencionados oito vezes.

A preocupação dos profissionais com assuntos sobre a própria atividade e o meio em que irão exercer suas atividades proporciona uma melhor qualidade sobre o que irão desenvolver no meio rural, até porque a ação extensionista se dá no domínio humano, em que a extensão de seus conhecimentos e técnicas se faz para inovar e transformar realidades com melhores condições de vida (Silva et al., 2015. BROSLER et al., 2010, p.2).

Essa é a importância de se gerar conhecimentos ara a geração de inovação no sentido da diversificação da agricultura familiar, da organização coletiva e da inclusão das famílias de agricultores em mercados. Como processo, conforme Peixoto (2008), a ATER seria um meio de estender, levar ou transmitir conhecimentos via capacitações, sendo estes conhecimentos técnicos ou não, através de estruturas geradoras (instituições públicas, cooperativas, empresas...), para o receptor final (o agricultor familiar). E o extensionista sendo o mediador desses conhecimentos entre a instituição e o agricultor.

Questionados da necessidade de realizar capacitações para executar bem suas atividades na agricultura familiar do Rio Grande do Norte, 92\% dos entrevistados responderam que "sim", e $8 \%$ responderam que "não", conforme gráfico 5. Os profissionais que responderam "sim", mostraram interesse em capacitações específicas da formação que possuem. Diante disso, as necessidades de capacitações surgem como um meio de mostrar que são indispensáveis para o 
aprendizado contínuo do extensionista, pois os técnicos de ATER são agentes de mudança e devem estar capacitados para capacitar pessoas e desempenhar suas atividades com excelência.

Gráfico 5 - Necessidade de capacitações para a geração de inovação na agricultura familiar

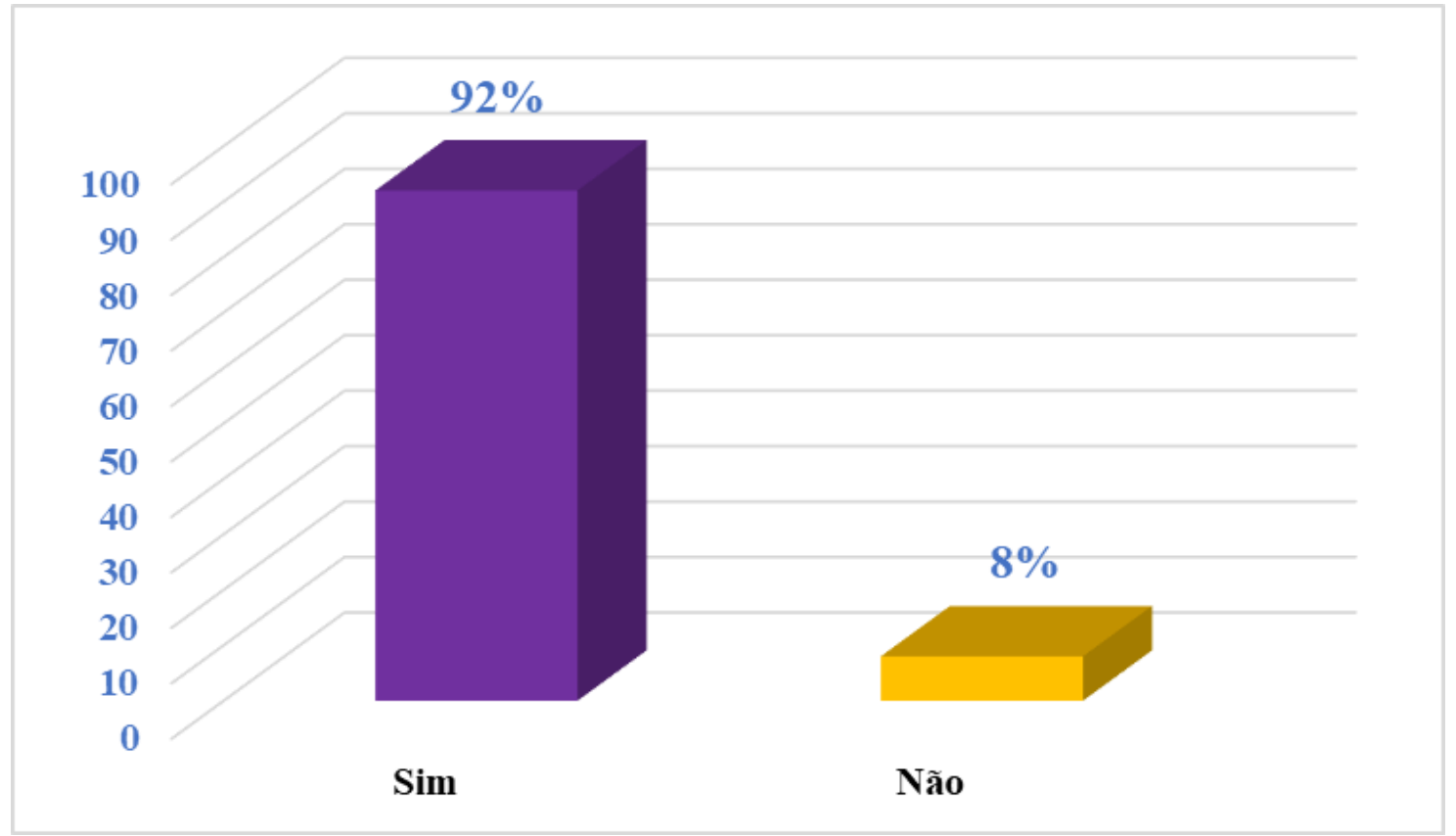

Fonte: Elaboração dos autores a partir de EMATER-RN (2016).

Os conhecimentos direcionados aos bolsistas/extensionistas da EMATER-RN estão alinhados com a nova política de ATER, preconizada pela PNATER junto ao MDA, a qual sugere que a ação de ATER seja traduzida num contínuo processo de formação de formadores. Para isso, requer dos extensionistas a aplicação de metodologias mais participativas por meio de uma pedagogia humanista, tendo como principal elemento a realidade e o conhecimento do local em que estão inseridos. E a ação de ATER, expressa nos resultados da pesquisa, destaca o interesse pelos conhecimentos sobre Extensão Rural e as políticas que desenvolve. Esse é o direcionamento da EMATER-RN para a tentativa da integração das ações de ATER com políticas no sentido de gerar inovação e construir mercados para a agricultura familiar. E o alcance dessa integração passa pela constante e contínua capacitação e aprendizado entre extensionistas e os agricultores familiares, quando da operacionalização de políticas de mercado, a exemplo do PNAE e do PAA. Cabe ressaltar que o acesso a mercados pela agricultura familiar exige desdobramentos da ação de ATER, os quais são considerados inovações, como acesso e bom uso do crédito, organização coletiva e procedimentos legais que levam à certificação de produtos, como Serviços de Inspeção Municipal (SIM), Estadual (SIE) e Federal (SIF). 


\section{CONSIDERAÇÕES FINAIS}

Em um primeiro momento, a pesquisa permitiu constatar na seleção de técnicos/bolsistas da EMATER uma clara mudança de concepção para as ações de ATER no Rio Grande do Norte, onde se deixa de lado o antigo difusionismo característico da modernização agrícola, e é abraçada a nova concepção da PNATER do extensionismo. Outro ponto foram os requisitos necessários para a atuação dos bolsistas/extensionistas da EMATER/RN durante 24 meses e quais as formações para a atuação dos profissionais.

A pesquisa revelou as profissões diversificadas, divididas entre as áreas das ciências sociais e ciências agrárias, e que os conhecimentos necessários para a execução das atividades fossem no sentido de gerar inovação e diversificação no âmbito da agricultura familiar, visando engendrar processos em dinâmicas regionais de desenvolvimento rural no Rio Grande do Norte. Dessa forma, segundo os critérios estabelecidos, se faz necessário formação técnica, tecnóloga ou ensino superior, não precisamente na área das ciências agrárias, onde percebeu-se que a maior parte dos profissionais possui formação técnica, e em sua maioria são técnicos em agropecuária.

No segundo momento observou-se uma preocupação dos bolsistas/extensionistas com conhecimentos, onde prevaleceram temas sobre a própria Extensão Rural e as políticas públicas integradas às ações de ATER. $O$ destaque foi para a integração das ações de ATER com as políticas, onde a geração de inovações levaria a inclusão de famílias de agricultores e a construção de mercados para a agricultura familiar, a exemplo do acesso ao crédito, organização coletiva, PAA e do PNAE e seus desdobramentos. Quanto as capacitações, a maior parte dos profissionais ao serem questionados se havia a necessidade destas, demonstraram uma preocupação em se capacitarem em assuntos específicos da graduação que possuem. Essa demonstração de interesse se justifica, pois, o extensionista é o agente com credencial para a mudança de realidades no âmbito da agricultura familiar do Rio Grande do Norte. E a partir da nova concepção de ATER, que reforça o extensionismo, e leva à troca e complementação do conhecimento científico (extensionistas) com a sabedoria popular (agricultor), onde os dois devem manter o aprendizado contínuo e estarem capacitados para capacitar ainda mais pessoas.

Diante disso, partindo deste trabalho, as próximas seleções da EMATER-RN podem ser aperfeiçoadas, e considerar que profissionais já possuam conhecimentos necessários para gerar inovação e engendrar processos em dinâmicas regionais de desenvolvimento rural, pois, o período de 24 meses, pode ser curto para capacitálos e torna-los aptos para desenvolverem as ações de ATER para transformem a realidade da agricultura familiar. 


\section{REFERÊNCIAS}

ANDRADE, R. Teoria do Capital Humano e Qualidade da Educação nos Estados Brasileiros. 2010. 73f. Monografia - UFRGS. Porto Alegre, 2010.

BRASIL. Diário Oficial do Rio Grande do Norte. Edital Funcitern/EMATER/RN No002/2016. Disponível em: http://www.diariooficial.rn.gov.br/dei/dorn/docview.aspx?id_jor=00000001\&data=2 0161224\&id_doc $=558821$. Acesso em: 20 de out. de 2018.

BRASIL. Instituto Brasileiro de Geografia e Estatística. Área Territorial, População Estimada. Disponível em: https://www.ibge.gov.br/estatisticas-novoportal/porcidade-estado-estatisticas.html?t=destaques\&c=24 Acesso em: 20 de set. de 2018.

BRASIL. Instituto de Assistência Técnica e Extensão Rural. Escritórios Regionais. Disponível em: http://www.emater.rn.gov.br/Conteudo.asp?TRAN=ITEM\&TARG=149288\&ACT=\&PA $\mathrm{GE}=0 \& P A R M=\& L B L=E s c r i t \% F 3$ rios+regionais Acesso em: 19 de set. 2018.

BRASIL. Instituto de Assistência Técnica e Extensão Rural. Histórico. Disponível em: http://www.emater.rn.gov.br/Index.asp Acesso em:19 de set. de 2018.

CAPORAL, F. R.; RAMOS, L. F. Da Extensão Convencional à Extensão Rural para o Desenvolvimento Sustentável: Enfrentar Desafios Para Romper a Inércia. Disponível em: http://agroecologia.pbworks.com/f/Artigo-Caporal-LadjaneVers\%C3\%A30Final-ParaCircular-27-09-06.pdf Acesso em: 18 de set. 2018.

\section{CAPORAL. F. R. A Extensão Rural e os Limites a Prática dos Extensionistas do} Serviço Público. 1991. 134 p. Dissertação (Mestrado em Extensão Rural) - Curso de Pós-Graduação em Extensão, Universidade Federal de Santa Maria, Santa Maria, 1991.

CASTRO, C. N.; PEREIRA, C. N. Agricultura Familiar, Assistência Técnica e Extensão Rural e a Política Nacional de Ater. Brasília: IPEA, Texto para Discussão, n² 2343, 2017.

GIL, A. C. Métodos e Técnicas de Pesquisa Social: 6. ed. São Paulo: Atlas S.A, 2008.

GRISA, C.; SCHNEIDER, S. Três gerações de políticas públicas para a agricultura familiar e formas de interação entre sociedade e Estado no Brasil. In: GRISA, C.; SCHNEIDER, S. (Org.). Políticas públicas de desenvolvimento rural no Brasil. Porto Alegre: Editora da UFRGS, 2015. p. 19-50.

MINCER, Jacob. Investment in human capital and personal income distribution. Journal of Political Economy. v. 66, n. 4, ago. 1958. 
MIRANDA, D. L. R.; GOMES, B. M. A. Desenvolvimento Rural e Políticas Públicas: um estudo de caso no Vale do Ribeira, PR, Brasil. Revista Brasileira de Desenvolvimento Territorial Sustentável. Guaju, Matinhos, v.2, n.2, p. 75-88, jul./dez. 2016.

NUNES, Emanoel Márcio et al. Novidades (Novelty) na Agricultura Familiar e sua associação com a agroecologia na produção de hortifrutigranjeiros no Território Sertão do Apodi (RN). Redes (St. Cruz Sul, Online), Santa Cruz do Sul, v. 23, n. 1, p. 213-236, jan. 2018. ISSN 1982-6745. Disponível em:

https://online.unisc.br/seer/index.php/redes/article/view/9292 Acesso em: 22 mar. 2020. Doi: https://doi.org/10.17058/redes.v23i1.9292.

NUNES, Emanoel Márcio; TÔRRES, F. de L.; SILVA, M. R. F. da; SA, V. C.; GODEIRONUNES, K. F. Dinamização Econômica e Agricultura Familiar: limites e desafios do apoio a Projetos de Infraestrutura (PROINF) em territórios rurais do Nordeste.

Revista de Economia e Sociologia Rural [Impresso], v. 53, p. 529-554, 2015.

OLIVEIRA, G. B. Uma Discussão Sobre o Conceito de Desenvolvimento. Revista da FAE, Curitiba, v. 5, n. 2, p. 37-48, 2002.

PEIXOTO, M. Extensão rural no Brasil: uma abordagem histórica da legislação. Senado Federal: Textos para Discussão n 48, 27 p., 2008.

PERROUX, F. A economia do século XX. Lisboa: Livraria Morais, 1967.

SEN, A. K. Desenvolvimento como Liberdade. São Paulo: Companhia das Letras, 2000.

SCHNEIDER, S. Situando o desenvolvimento rural no Brasil: o contexto e as questões em debate. Revista de Economia Política, vol.30. no.3. São Paulo July/Sept. 2010.

SCHULTZ, T. W. O Capital Humano: Investimento, Educação e Pesquisa. 1 ed. Rio de Janeiro: Zahar, 1973. p.250.

SILVA et. al. Formação Profissional e Elementos da Nova Ater: Um estudo com educandos do curso Técnico em Agropecuária. Revista Cadernos de Educação. no. 51. 2015.

VIANA, G.; LIMA, J. F. Capital Humano e Crescimento Econômico. Disponível em: http://www.scielo.br/pdf/inter/v11n2/a03v11n2 Acesso em: 12 de set. de 2018. 
Emanoel Márcio Nunes. Economista. Doutor em Desenvolvimento Rural pela Universidade Federal do Rio Grande do Sul (PGDR/UFRGS). Professor da graduação de Economia e do Programa de Pós-Graduação em Economia Aplicada (PPE/UERN) da Faculdade de Ciências Econômicas da Universidade do Estado do Rio Grande do Norte (FACEM/UERN).emanoelnunes@uern.br

Vivian Menezes da Silva. Economista. Mestranda em Planejamento e Dinâmicas Territoriais no Semiárido, pela Universidade do Estado do Rio Grande do Norte (PLANDITES/UERN).

Vinicius Claudino de Sá. Administrador. Doutor em Extensao Rural pela Universidade Federal de Santa Maria (PGExRural/UFSM). Professor da graduação de Administração da Faculdade de Ciências Econômicas da Universidade do Estado do Rio Grande do Norte (FACEM/UERN).

Como citar: NUNES, Emanoel Márcio; SILVA, Vivian Menezes da; SÁ, Vinicius Claudino de. Assistência Técnica e Extensão Rural (ATER): formação e conhecimentos para a agricultura familiar do Rio Grande do Norte. Redes (St. Cruz Sul, Online), Santa Cruz do Sul, v. 25, n. 2, p. 857-881, maio 2020. ISSN 1982-6745. Disponível em: https://online.unisc.br/seer/index.php/redes/article/view/14174 Acesso em: 22 maio 2020. doi: https://doi.org/10.17058/redes.v25i2.14174

\section{CONTRIBUIÇÃO DE CADA AUTOR}

a. Fundamentação teórico-conceitual e problematização:Emanoel Márcio Nunes, Vívian Menezes da Silva e Vinícius Claudino de Sá

b. Pesquisa de dados e análise estatística: Emanoel Márcio Nunes, Vívian Menezes da Silva e Vinícius Claudino de Sá

c. Elaboração de figuras e tabelas: Vívian Menezes da Silva e Vinícius Claudino de Sá

d. Fotos:Não se aplica

e. Elaboração e redação do texto: Emanoel Márcio Nunes e Vívian Menezes da Silva

f. Seleção das referências bibliográficas: Emanoel Márcio Nunes e Vívian Menezes da Silva

Fontes de financiamento

Conselho Nacional de Desenvolvimento Científico e Tecnológico - CNPq (com auxílio financeiro a projeto de pesquisa e bolsas de Iniciação Científica)

Fundação de Amparo à Pesquisa do Rio Grande do Norte - FAPERN (com bolsas de pósgraduação) 